\title{
PENENTUAN KOEFISIEN SERAP BUNYI PAPAN PARTIKEL DARI LIMBAH PELEPAH KELAPA SAWIT
}

\begin{abstract}
Abdi Setia Putra
Program Studi Teknik Mesin, Fakultas Teknik, Universitas Muhammadiyah Riau

Jalan Tuanku Tambusai Ujung, Kecamatan Tampan, Kelurahan Delima, Kota Pekanbaru, Riau 28291

E-mail: abdisetiaputra46@gmail.com

Abstract

The study is done to determine the characteristics of the material absorbs the particle board made of palm oil to the midrib 0,6 0,4 density and 0,9 $\mathrm{gr} / \mathrm{cm} 3$ adhesive with variations $15 \%$ and $20 \%$ adhesive urea and formaldehyde in use. Frequencies used is 125,250,500,1000, and $1200 \mathrm{hz}$. Value the absorption of sample made showing the price qualified according to sample ISO 11654 to classify it as a silencer and included in a category class the quality $c$. Research aims to understand characteristic of the coefficients employ the board particles of material midrib palm. Employ procedure test the were based on standard ASTM E1050-98 using the of tube impedance 2 microphone. Sample of measuring diameter \pm 99 mm. value density large frequency $(\mathrm{hz}$ ) good affect on value the coefficients employ the $(\alpha)$. Employ a value the will decrease in frequency 1000-1200hz and in density $\mathrm{gr} 0,9 / \mathrm{cm} 3$
\end{abstract}

Keywords: Sound Absorption Coefficient, Particle Board, Waste, Palm Oil Fruit

\begin{abstract}
Abstrak
Penelitian ini dilakukan untuk menentukan karakteristik koefisien absorbs bunyi dari material papan partikel yang terbuat dari pelepah kelapa sawit dengan kerapatan 0,4 0,6 dan 0,9 gr/cm3 Dengan variasi perekat $15 \%$ dan $20 \%$ perekat yang di gunakan yaitu urea formaldehida. Rentang frekuensi yang digunakan adalah 125,250,500,1000, dan $1200 \mathrm{~Hz}$. Nilai koefisien penyerapan dari sampel yang dibuat menunjukkan harga yang memenuhi syarat menurut ISO 11654 untuk mengklasifikasikan sampel tersebut sebagai peredam suara dan termasuk dalam kategori kelas kualitas C. Penelitian ini bertujuan untuk mengetahui karakteristik koefisien serap bunyi papan partikel dari bahan pelepah sawit. Prosedur uji serap bunyi dilakukan berdasarkan standar ASTM E1050-98 dengan menggunakan peralatan berupa tabung impedansi 2 mikrofon. Sampel uji berukuran diameter $\pm 99 \mathrm{~mm}$. nilai kerapatan besar frekuensi (Hz) sangat berpengaruh terhadap nilai koefisien serap bunyi $(\alpha)$. Nilai koefisien serap bunyi akan menurun di frekuensi 1000 - $1200 \mathrm{~Hz}$ dan pada kerapatan $0,9 \mathrm{gr} / \mathrm{cm} 3$
\end{abstract}

Kata kunci : Koefisien Serap Bunyi, Papan Partikel, Limbah, Pelepah Kelapa Sawit

\section{Pendahuluan}

\subsection{Latar Belakang}

Dengan semakin majunya teknologi, perkembangan peralatan yang di gunakan manusia semakin meningkat. Baik peralatan tersebut berupa sarana informasi, komunikasi, produksi, tansportasi maupun hiburan. Sebagian besar peralatan tersebut menghasilkan suara-suara yang tidak diinginkan, Gelombang bunyi dihasilkan oleh benda yang bergetar sehingga menyebabkan gangguan kerapatan pada medium. Gangguan ini berlangsung melalui interaksi molekul molekul medium sepanjang arah perambatan gelombang. Molekul hanya bergetar ke depan dan ke belakang di sekitar titik kesetimbanganya.

Keras lemahnya bunyi berbeda-beda bergantung pada sumber bunyi. Faktor keras lemah tersebut akan menimbulkan kebisingan. Kebisingan dapat direduksi dengan menggunakan material yang dapat meredam dan menyerap bunyi. Material penyerap bunyi yang ada di pasaran kebanyakan terbuat dari bahan sintetik. Salah satu kriteria bahan penyerap bunyi adalah berpori yang berfungsi sebagai resonator rongga. Melalui pori-pori ini gelombang suara masuk dan menggetarkan molekul-molekul udara di dalam pori tersebut (Simatupang, 2007). Untuk mengatasi hal tersebut di kembangkan berbagai 
jenis bahan peredam suara yaitu diantaranya adalah membuat panel akustik. Di samping itu peredam suara juga dibutuhkan untuk menciptakan bangunan atau gedung dengan karakteristik akustik tertentu sehingga tercipta kenyamanan bagi penggunanya (Aini khurati,2006).

Untuk mengurangi kebisingan, dapat digunakan bahan yang berfungsi untuk menyerap suara dan insulasi suara sehingga kualitas suara yang terdengar dapat lebih terkontrol. Kualitas dari bahan penyerap suara ditunjukkan dengan nilai $\alpha$ (koefisien absorbsi suara). Koefisien absorbsi suara merupakan perbandingan antara energi suara yang diserap oleh bahan terhadap energi suara yang menuju permukaan bahan (Sarwono 2009). Semakin besar $\alpha$, maka bahan tersebut semakin baik digunakan sebagai peredam suara. Nilai $\alpha$ berkisar dari 0 sampai 1 . Jika $\alpha$ bernilai 0 , artinya tidak ada bunyi yang diserap. Sedangkan jika $\alpha$ bernilai 1 , artinya $100 \%$ bunyi yang datang diserap oleh bahan (Lee dan Joo 2003). Insulasi suara merupakan kemampuan bahan dalam mereduksi suara, atau dikenal sebagai rugi transmisi suara (sound transmission loss, STL). STL juga dapat diartikan sebagai perbandingan antara suara yang ditransmisikan oleh suatu bahan terhadap suara yang datang (Elang Shandi Kusuma.2012).

Material yang mengandung segnoselulosa mempunyai daya serap yang baik terhadap bunyi (Metalurgical Physics, 2011). Karlinasari et al. (2010) melakukan penelitian mengenai sifat penyerapan dan isolasi suara berkerapan sedangtinggi dari (2013) dengan menggunakan serat daun nenas sebagai bahan dasar, mendapatkan hasil semakin besar kerapatan (density) papan serat daun nenas maka akan semakin rendah nilai koefisien serapan bunyinya.

Pelepah kelapa sawit merupakan salah satu bahan organik yang sangat mungkin untuk digunakan sebagai material penyerap bunyi. Buah kelapa sawit mempunyai banyak jenis varietas. Dilihat dari fisiknya, pelepah kelapa sawit berserabut dan ringan, sehingga sangat mungkin untuk dikembangkan sebagai material bahan penyerap bunyi.

Papan partikel adalah panel-panel kayu yang terbuat dari bahan berlignoselulosa dalam bentuk potongan-potongan kecil atau partikel dari serat yang dicampur dengan perekat sintetis atau bahan pengikat lain yang direkat dengan metode pengempaan (Maloney 1993). Material penyerap bunyi yang baik diperoleh dari bahan yang berpori (porous) dimana dihasilkan intermolekuler friksi atau gesekan saat gelombang suara mengenai bahan (McMullan 2002; Bucur 2006).

Suheami Thamrin (2013) menyatakan koefisien serap bunyi papan partikel dari bahan sabut kelapa, di dapat kesimpulan dari penelitian ini bahwa ketebalan sampel mempengaruhi nilai koefisien serap bunyi $(\alpha)$ yaitu pada frekuensi 600 Hz. Koefisien serap bunyi $(\alpha)$ semakin menurun dengan bertambahnya ketebalan papan partikel (sampel penyerap). Obimita Ika Permatasari (2014) menyatakan dalam pembuatan papan partikel sebagai alat penyerap suara (panel akustik) ada beberapa hal yang perlu di perhatikan, yaitu kadar campuran perekat dan kerapatan papan partikel hal ini sangat menentukan sifat akustik dari papan partikel tersebut.

\section{Methodologi}

Bahan yang di gunakan yaitu Pelepah kelapa sawit yang telah di cacah dengan ukuran lebih dari $3 \mathrm{~mm}$ dan Perekat urea formaldehida dengan variasi perekat $15 \%$ dan $20 \%$.

Alat sederhana yang digunakan untuk menguji sampel terbuat dari pralon berbentuk tabung. Tabung di rancang untuk mengukur parameter akustik suatu bahan dengan ukuran material uji sesuai ukuran tabung dan suara datang pada arah normal.

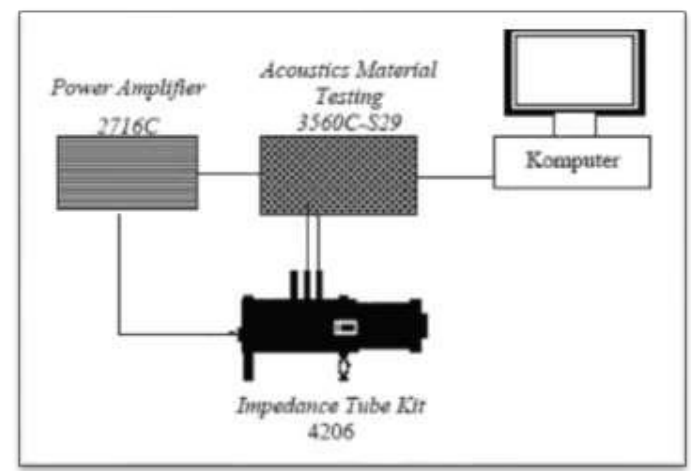

Adapun langkah langkah yang akan di kerjakan dalam penelitian ini adalah menyiapkan spesimen uji berbentuk lingkaran dengan diameter $\varnothing$ $99 \mathrm{~mm}$ dan ketebalan $1 \mathrm{~cm}$. Sampel uji yang di gunakan menggunakan variasi bahan perekat dan kerapatan papan partikel dengan variasi sampel P1K1, P1K2, P1K3, dan P2K1, P2K2, $\mathrm{P} 2 \mathrm{~K} 3$, 


\begin{tabular}{|c|c|c|}
\hline No & Perekat & Kerapatan \\
\hline 1 & $15 \%$ & $0,4 \mathrm{gr} / \mathrm{cm}^{3}$ \\
\hline 2 & $15 \%$ & $0,6 \mathrm{gr} / \mathrm{cm}^{3}$ \\
\hline 3 & $15 \%$ & $0,9 \mathrm{gr} / \mathrm{cm}^{3}$ \\
\hline 4 & $20 \%$ & $0,4 \mathrm{gr} / \mathrm{cm}^{3}$ \\
\hline 5 & $20 \%$ & $0,6 \mathrm{gr} / \mathrm{cm}^{3}$ \\
\hline 6 & $20 \%$ & $0,9 \mathrm{gr} / \mathrm{cm}^{3}$ \\
\hline
\end{tabular}

\section{Hasil dan Pembahasan}

Sampel uji terdiri dari dua kadar perekat dan tiga jenis kerapatan yang berbeda dalam setiap sampel. Dari sampel yang telah dibuat, hanya dilakukan pengujian koefisien penyerapan untuk 6 sampel yaitu P1K1,P1K2,P1K3 dan $\mathrm{P} 2 \mathrm{~K} 1, \mathrm{P} 2 \mathrm{~K} 2, \mathrm{P} 2 \mathrm{~K} 3$ dengan pengujian serap suara yang dilakukan pada frekuensi rendah yaitu $125,250,500,1000,1200 \mathrm{~Hz}$.

$\mathrm{P} 1 \mathrm{~K} 1=$ PEREKAT $15 \%$ KERAPATAN $0.4 \mathrm{gr} / \mathrm{cm} 3 \quad \mathrm{P} 1 \mathrm{~K} 2=$ PEREKAT $15 \%$ KERAPATAN $0.6 \mathrm{gr} / \mathrm{cm} 3 \mathrm{P} 1 \mathrm{~K} 3=$ PEREKAT $15 \%$ KERAPATAN $0.9 \mathrm{gr} / \mathrm{cm} 3 \quad \mathrm{P} 2 \mathrm{~K} 1=$ PEREKAT 20\% KERAPATAN $0.4 \mathrm{gr} / \mathrm{cm} 3 \mathrm{P} 2 \mathrm{~K} 2$ $=$ PEREKAT $20 \%$ KERAPATAN $0.6 \mathrm{gr} / \mathrm{cm} 3$ $\mathrm{P} 2 \mathrm{~K} 3=$ PEREKAT $20 \%$ KERAPATAN $0.9 \mathrm{gr} / \mathrm{cm} 3$

Dari hasil pengujian yang dilakukan untuk menentukan koefisien absorbsi bunyi material akustik diperoleh nilai koefisien absorbsi bunyi yang berbeda-beda untuk masing-masing sampel.

\subsection{Sample P1 (kadar perekat 15\%).}

Hasil pengujian koefisien serap bunyi untuk beberapa jenis pelepah sawit dengan komposisi $15 \%$ perekat, kerapatan $0.4,0.6,0.9 \mathrm{gr} / \mathrm{cm} 3$, dan rentang frekuensi antara $125-1200 \mathrm{~Hz}$ dapat dilihat pada Gambar dibawah ini.

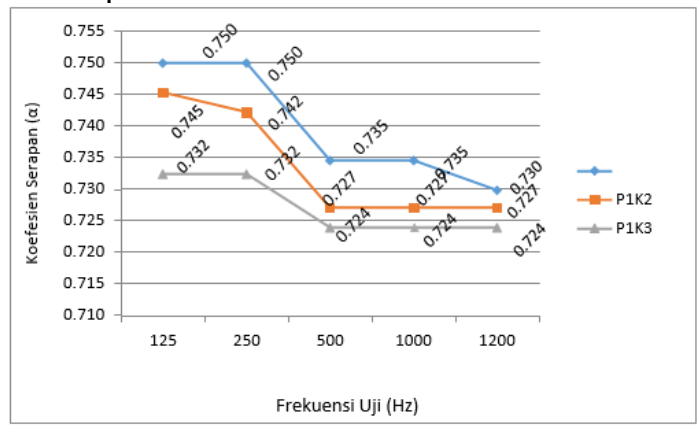

Gambar 3.1.
Pada Gambar 3.1 dapat dilihat bahwa pada frekuensi dari $500 \mathrm{~Hz}$ ke $1200 \mathrm{~Hz}$ untuk semua jenis papan partikel pelepah kelapa sawit mengalami penurunan koefisien serap.Untuk frekuensi 500,1000 dan $1200 \mathrm{~Hz}$ nilai koefisien serap bunyi cenderung terjadi penurunan nilai, Koefisien serap bunyi terbaik terdapat pada frekuensi 125 dan $250 \mathrm{~Hz}$. Untuk jenis kerapatan papan partikel sample pada kerapatan 0.4 memiliki nilai koefisien tertinggi yaitu paling tinggi 0.750 pada frekuensi 125 ,dan $250 \mathrm{~Hz}$, dan nilai koefisien serap bunyi terendah pada sample dengan kerapatan 0.9 yaitu 0.724 pada frekuensi 500-1200 Hz.

\subsection{Hasil untuk sample P2 (kadar perekat $20 \%$ )}

Hasil pengujian koefisien serap bunyi untuk beberapa jenis papan partkel pelepah sawit dengan komposisi 20\%, kerapatan 0.4, 0.6, 0.9 $\mathrm{gr} / \mathrm{cm} 3$ dan rentang frekuensi antara $125-1200$ $\mathrm{Hz}$ dapat dilihat pada Gambar dibawah ini.

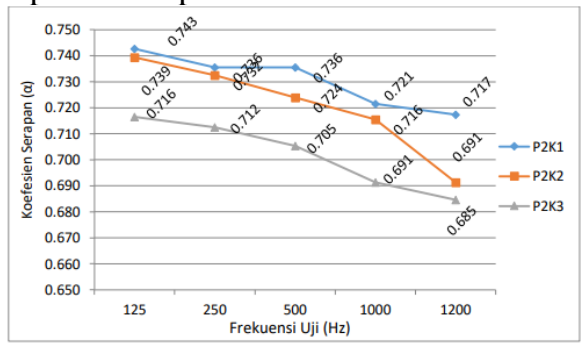

Gambar 3.2.

Pada gambar 3.2 di dapatkan setiap sample pada kerapatan yang berbeda sample mengalami penurunan koefisien serap bunyi pada frekuensi tinggi, yaitu daya serap bunyi tertinggi terdapat pada sample P2K1 yaitu 0.743 pada frekuensi 125 $\mathrm{Hz}$ dan daya serap bunyi terendah terdapat pada sample P2K3 yaitu 0.685 pada $1200 \mathrm{~Hz}$. Pada setiap sample semua mengalami penurunan koefisien serap bunyi pada frekuensi tinggi dan nilai koefisien tertinggi terdapat pada kerapatan $0.4 \mathrm{gr} / \mathrm{cm} 3$ (0.743), lalu $0.6 \mathrm{gr} / \mathrm{cm} 3$ (0.739), dan $0.9 \mathrm{gr} / \mathrm{cm} 3(0.716)$.

3.3 Pembahasan.

Pembahasan Berdasarkan hasil penelitian koefisien penyerapan bunyi bahan akustik dari pelepah kelapa sawit menunjukan bahwa bahan akustik dari pelepah kelapa sawit bisa menyerap bunyi. Hal ini karena karakteristik dari serat pelepah kelapa sawit bisa di gunakan sebagai pengganti bahan penyerap suara dari serbuk kayu. Sehingga pelepah kelapa sawit yang di jadikan serbuk ini memenuhi syarat sebagai papan akustik penyerapan bunyi.

Nilai minimum bahan untuk dapat dikatagorikan sebagai peredam suara menurut

SURYA TEKNIKA Vol. 7 No. 2, Desember 2020: 182-185 
ISO 11654 adalah 0.15 . Nilai aw koefisien penyerapan dari sampel yang dibuat (grafik 1 dan 2) menunjukkan harga yang memenuhi syarat menurut ISO 11654 untuk mengklasifikasikan sampel tersebut sebagai peredam suara dan termasuk dalam kategori kelas kualitas C.

Analisa grafik hubungan antara kerapatan papan dengan koefisien serap bunyi pada gambar grafik 4.1 dan 4.2, menunjukan bahwa semakin pada padat bahan yang di gunakan semakin kecil nilai koefisien yang di hasilkan. Hal ini karena gelombang bunyi yang berjalan pada medium rapat pada serbuk pelepah kelapa sawit yang telah di haluskan lalu di pres dengan menggunakan perekat akan memadat dan akan sangat rapat hal ini akan membuat pori pori pada material akan semakin sedikit gelombang frekuensi yang di terima oleh material akan susah menembus susunan atom partikel dan terpantulkan $(0<\alpha<1)$.

Namun frkuensi yang di terima sangat berpengaruh juga hal ini terlihat dari ke enam sample dengan perkat dan kerapatan yang berbeda yang mana pada frekuensi tinggi yaitu $500 \mathrm{~Hz}$, $1000 \mathrm{~Hz}$ dan $1200 \mathrm{~Hz}$ nilai absorsi cenderung menurun, hal ini bisa terjadi akibat proses manufaktur yang kurang baik. Sesuai dengan penelitian Dharmantya (2010), tingkat serapan bunyi yang dihasilkan oleh masing-masih sampel berbeda dipengaruhi oleh kerapatan dan poripori udara dalam sampel tersebut. Semakin besar kerapatan, energi bunyi akan sulit menembus material tersebut karena porositasnya kecil, kecepatan partikel bunyi kecil dan impedansinya besar sehingga bunyi lebih banyak dipantulkan dari pada diserap (Kinsler \& Frey 1982 dalam Obimita 2014) kadar perekat $15 \%$ dari masing masing jenis kerapatan lebih baik dari jumlah kadar perekat $20 \%$. Terlihat pada grafik 4.1 dan 4.2 hal ini di sebabkan oleh prtikel pelepah sawit yang di ikat dengan kadar perekat yang lebih banyak akan sulit buat di lewati gelombang bunyi sehingga gelombang yang di serap akan lebih banyak terpantulkan oleh prtikel perekat.

\section{Simpulan}

Setelah melakukan penelitian analisa penentuan koefisien serap bunyi papan partikel komposit dari limbah pelepah kelapa sawit dengan menggunakan perekat urea formaldehida di peroleh kesimpulan sebagai berikut :

1. Semakin tinggi frekuensi yang di berikan maka semakin kecil nilai serapan bunyi papan partikel,begitupun sebaliknya.
2. Jumlah kadar perekat mempengaruhi nilai serap bunyi papan partikel yang mana semakin tinggi kadar perekat maka akan semakin rendah daya serap bunyi papan partikel,

3. Semakin besar nilai (density) kerapatan pada papan partikel maka akan semakin kecil nilai koefisien serap bunyi papan partikel dari pelepah kelapa sawit begitupun sebaliknya.

4. Nilai koefisien penyerapan dari sampel yang dibuat menunjukkan harga yang memenuhi syarat menurut ISO 11654 untuk mengklasifikasikan sampel tersebut sebagai peredam suara dan termasuk dalam kategori kelas kualitas C.

\section{Daftar Pustaka}

[1] Aini Khuriati.2006.Disain Peredam Suara Berbahan Dasar Sabut Kelapa dan Pengukuran Koefisien Penyerapan Bunyinya.

[2] Djoko Purwanto.2016,Sifat fisis dan mekanis papan partikel dari limbah campuran serutan rotan dan serbuk kayu.

[3] Dwi Aries Himawanto. 2007.KARAKTERISTIK PANEL AKUSTIK SAMPAH KOTA PADA FREKUENSI RENDAH DAN FREKUENSI TINGGI AKIBAT VARIASI KADAR BAHAN ANORGANIK.

[4] Eka Roy Jayanto. 2011. Potensi serat buah pinang sebagai pengisi penguat komposit polyester dengan menggunakan katalis metil etil keton peroksida.

[5] Elang Sandhi Kusuma.2012.PENGUJIAN PANEL AKUSTIK PAPAN PARTIKEL KAYU SENGON (Paraserianthes falcataria)

[6] Evi indrawati. 2009.Koefisien penyerapan bunyi bahan akustik dari pelepah pisang dengan kerapatan yang berbeda.

[7] ISO 11654:1997, (BRITISH STANDARD International Organization for Standardization). Sound absorbers for use in buildings - Rating of sound absorption.

[8] Obimita Ika Permatasari,Penentuan koefisien serap bunyi papan partikel dari limbah tongkol jagung.

[9] Suharyani, Dhani Mutiari. 2013, Limbah pelepah pisang raja susu sebagai alternatif bahan dinding kedap suara.

[10]Suheamy Thamrin. 2003, Koefisien serap bunyi papan partikel dari bahan serbuk kayu kelapa 